\title{
Informed consent in contemporary dental photography - ethics and law
}

\author{
Radostina Vasileva ${ }^{1}$, Gergana Petrova ${ }^{2}$, Rossen \\ Kolarov ${ }^{3}$, Nikolay Nikolov ${ }^{4}$.
}

1. Department of Prosthetic Dentistry, Faculty of Dental Medicine, Medical University - Varna;

2. Inspector in an administrative unit: Directorate: "Control of compliance with patient rights" under Executive Agency "Medical Audit", Bulgaria;

3. Department of Oral and Maxillofacial surgery, Faculty of Dental Medicine, Medical University Varna;

4. Private dental practice - Plovdiv.

\section{Abstract}

The aim of this article is to conduct research on issues and common strategies to protect the privacy of patients when using dental photographs for educational and clinical purposes, and to prepare a specialized form of informed consent.

Methods: 1. Documentary method; 2. Consultation with a legal expert; 3. Statistical method.

Results: The results of the documentary and statistical survey are indicative of the need to implement the informed consent using dental photography in dentistry, to avoid bilateral ambivalent reactions. The informed consent form is consistent with the ethical and legal concepts of modern dentistry.

Conclusion: The modern dental photography has a major role in the process of educating and qualifying dentists and the experts in dental medicine. The photographic documentation and its aspects, purposes and availability impose it as a modern method of comparing analysis when taking pictures of the patient before, during and after dental treatment. The obligation of dentists to present information for the rights of the patient when using dental photography is a major part of the modern medical treatment. The implementation and defence of the mentioned human rights, structured in the state constitution, depend mostly on the knowledge of the patients about dental photography and their 
own activity as participants in the process. The protection of this public interest is placed whit in the priorities of the professional organization in order to enforce its effective and guarantee dental care according to the best dental practice.

\section{Keywords: dental photography, medical deontology, informed consent}

\section{Introduction}

The article is about the meaning of the term "Informed consent" in modern dental photography - as a significant part of medical practice. Mentioned here are the main issues of the patient's willingness in dental photography, the importance of informed consent and it's place in medical care and practice. Mentioned here are the regulatory requirements and legal hypotheses, governing the form of validity in agreement or disagreement of medical treatment.

The purpose of this article is to present view of the contents, preconditions and main elements of the term "Informed consent", which caused the implementation of dental photography compared to patient's agreement in dental treatment. We point out specific results, research, analysis and questionnaires on the subject. The specific information issues the conclusion that the expression of "Informed consent" of the person to whom dental photography is performed is associated more with educational and scientific purposes of images than with the actual treatment of the patient, which in tum determines the direction of this exposure.

The publication aims to examine the legal and deontological inherently figure of "Informed consent" in dental medicine, in a strongly changing social relations in the provision and use of medical services in Bulgaria. The changed nature of the legal relationship between a doctor and his/her patient, - on one hand, and doctor- student-patient-the, on the other, imposes a new review of the principles and the conditions in which they are implemented and the legal framework within which it takes place.

Dental photography is a current method of drawing up reliable documentation and the achievement of an objective clinical examination. It is suitable for every specialty in dentistry $(1,2,3,4,5)$.

Increasingly widespread use of photography these days has its leading role as a modern method as in dentistry and in education, communication, telemedicine, etc. Photography is an integral part of the dental education and is formed as the main method for training in dentistry. Over the years a number of professionals are aware of its importance. Back in 1945 Mandiwall $\mathrm{N}$. emphasized the paramount importance of visual education in the training of dentists $(6,7)$. In the 21st century, the ability to manufacture, storage, and distribute digital images is easily available to dentists. This leads to the imposition of the method dental photography as a significant and concomitant part in dentistry and training of dentists in our country and around the world. These positive changes are bound with various ethicalmoral, legal and deontological in character issues related to the personality and the right to privacy. In literature, changes in the medical photographic documentation and ethical-legal relationship between a dentist and his/her patient were considered in 1890. Even then, the authors talked about the respect of anonymity, documenting only affected by disease processes parts of the patient's body, and the obligation 
to remove the public information on the social background of the patient $(7,1)$. The debates about informed consent regarding particularly the application of dental photography in the treatment and especially training in dentistry are caused by the central importance of the right of every individual to be fully informed and to make a personal choice to be treated or to refuse-such. In this context, dental photography as a modern, contemporary and proven effective and are increasingly used method of acquiring clinical picture for the purposes of treatment, especially for training in dentistry requires discussion on the place and importance of "Informed consent" to dental photography.

Aim

1. The purpose of this article is to hold an examination on issues and common strategies to protect the privacy of patients using dental photographs for educational and clinical purposes.

2. To prepare a specialized form of an informed consent for dental photography with which to ensure the protection of both the patients and the medical professional in terms of the conformity of the applied photography and use for educational purposes of the acquired images of the method.

\section{Material and Methods}

1. Documentary method: Reviewing and analysis the literature on legal patients' issues relating to the use of dental photography in clinical practice and education.

2. Statistical method: Informed consent to dental photography, require compliance with the three main criteria: confidentiality, record keeping and authenticity of the images [1]. Conducting statistical survey on the attitudes of patients in Bulgaria to dental photography and reporting their opinion on the criteria: confidentiality and preservation of photographic documentation.

3. Consultation with a legal expert: Discussion with a legal expert in medical law issues related to informed consent and its place using dental photography in dental practice and education of medical professionals.

\section{Results and Discussion}

In order to identify the main aspects in the preparation of an informed consent using dental photography, we discussed issues related to patients' rights when using dental photography in dentistry, at a certain stage process.

Reviewing the available literature on legal patients issues relating to the use of dental photography in dentistry publications for this article were collected electronically. Electronic search was conducted in PubMed, Cross Ref., Electronic magazines in web-based directories such as Google Scholar (8).

Literature studying took place during June to August 2016 using the basic purpose of analyzing keywords suc as "informed consent", "dental photography", "clinical photography," "medical ethics", "patients' rights "and contains publications from 1999 to 2014. Analysing and reviewing the literature we clarified basic patient's legal and ethical principles in conformity which should be enclosed by expressed informed consent when dental photography is applied. 
The dynamics of the world shifted and deleted increasingly imposed belief that the physician does not perceive the patient as equal to themselves in social, economic, educational and intellectual sense. The attitudes of physicians change in terms of their knowledge and expertise in order to establish an asymmetrical relationship with the patient, where the doctor speaks, and the patient listens without questions and complaints. In modern deontological medical care, the consent of the patient is central among the issues for delivery of medical care in general. Receipt is a prerequisite that turns impact on the human body of criminal assault in the treatment of socially dangerous behavior a legally regulated profession, containing within itself a serious risk, which is borne to achieve higher public purpose - the preservation and restoration of human health.

The content of informed consent: his legal meaning and expression procedure - consultation with legal expert.

The principle of informed consent in medicine is globally recognized. It applies fully in the dentistry area same as discussed being proclaimed in art. 3 pt. 2 b. a.) the Charter of Fundamental Rights of the European Union (2007 / C 303/01),(9, 10, 11) and reads: "In the area of medicine and biology, should be respected in particular: a) the free and informed consent of the person concerned in certain statutory arrangements. "

This principle is essential in the European Convention of Human Rights and Biomedicine, which entered into force for the Republic of Bulgaria (Prom. SG. 32 of 12.04.2005), which states: Art. 5 of the Convention "Any intervention in the health field is carried out only with the free and informed consent of the person concerned. This person beforehand shall be given appropriate information on the purpose and nature of the intervention as well as its consequences and risks.

The informed consent of the Republic of Bulgaria is regulated in art. 87 et seq of the Health Act.(12,13) This is relatively modern inserted, in 2008 Bulgarian legislature supplemented in accordance with the Convention on Human Rights and Biomedicine, the Declaration to support the rights of patients (Amsterdam, 1995), the European Charter of Patients' Rights (Rome, 2002) and Recommendation 2000/5 of the Council of Europe which is seen as a fundamental and integral part of any democratic society the right of citizens and patients to participate in decisions concerning their health. These changes are in line with the universal right of citizens to the best possible state of physical and mental health guaranteed under Art. 12 para. 1 of the International Covenant on Economic, Social and Cultural Rights and the right to the best health that can be achieved - according to the Preamble of the Constitution of the World Health Organization.

Regulation of human rights in health care begins with the Constitution of the Republic of Bulgaria - the main and the highest ranking legislation. The general act regulating public relations related to the health of citizens is the Health Act regulating human health as general and the rights and obligations of the doctors and patients. National legislation regulates the legal figure of "informed consent" mainly in health law as special provisions contained in secondary legislation approved medical standards established rules of good medical practice in healthcare. Under the health medical activities are carried out after obtaining informed consent from the patient. $(15,16,17,18,19,20,21,22,23)$.

Pursuant to Art. 92, para. 1it pt. 3 of the Health Act, the doctor must inform the patient about the planned preventive activities and risks associated with them. Undoubtedly, this information is carried out in order to 
take informed consent regarding these preventive activities as art. 92 establishes and details art. 88 in terms of facts for which the physician must inform the patient, respectively his parent, guardian or custodian for obtaining informed consent.

With regard to medical activities related to surgical interventions, conditions of patients whose medicaldiagnostic process requires general anesthesia, invasive and other diagnostic and therapeutic methods that lead to increased risk to life and health of the patient or a temporary shift in consciousness, the legislature is detailed conditions, form validation, as well as elements of information and its volume. In such cases the legislator for the written form of the informed consent form for the reality of the orally expressed will, which is mandatory. Otherwise it is assumed that informed consent by the patient is not present, and raises the question of the intervention of the doctor in this case and legitimate is it? The law regulates the cases of exemption from the requirement for written informed consent that are exclusive and are required to preserve the life and health of the patient when:

- The patient's life is directly threatened;

- Their physical or mental condition does not allow expression of informed consent;

- Inability to timely obtain informed consent from individuals whose wishes replace the personal consent.

When the patient is a minor or incapacitated, informed consent is expressed by his parent or legal guardian, except in some cases provided by law. In people with mental disorders and established inability to express informed consent it shall be expressed by persons designated by the special procedure of the Health Act.

The law has provided the patient and reciprocal right of withdrawal. The right of withdrawal is associated with the free expressed will of the person with respect for the sovereignty of individual prohibition on applying medical measures against the will of the person. The patient, respectively person to whom the law delegates rights to express their will in the name of the person (parents in cases of infancy or immaturity, guardians, custodians) can refuse at any time the proposed medical care or continuing the medical activity that has already started. The Health Act has arranged for an exception to the right of withdrawal in Art. 90. The refusal of the patient is certified in writing by signature of the person in the accompanying medical documentation.

The issue to express informed consent in dental practice appears to be different. The Health Act, together with the imposed belief, both of dentists and the wider part of lawyers and patient community assumes that in providing dental care form to express informed consent is oral, except when patient treatment is associated with surgery.

Analyses in the sector of dentistry, drawn up in collaboration between the Executive Agency "Medical Audit"- Bulgaria (EAMAB) and the Bulgarian Dental Association, impose opinion about the mandatory nature of the statement of informed consent and her writing $(24,25)$.

Experts, representatives of EAMAB and Dental Association, prepared the analysis said that such a belief is imposed by the conclusion that local infiltration anesthesia under Art. 89, para. 1 of the Health Act appears and "invasive" and the legal definition of the term "invasive" presented by the legislature in $\S 1 \mathrm{p}$. 3 of the Supplementary Provisions constitutes "Invasive methods" are diagnostic and treatment 
instrumental techniques, that by violating the integrity of the skin and mucous membranes or through natural openings is penetrated into the human body.

Given those considerations of analysts, they accept that in the case of inserting a local (local) anesthesia characteristic mainly in the work of dentists, patients, respectively their parents or guardians must express their informed consent in writing. This is a mandatory requirement in connection with the use of anesthesia in modern methods of treatment in the dental practice.

The danger for physicians, both general and dentists in cases where a medical intervention without the expressed informed consent involves taking risks that are inherent for the intervention.

It is these risks taken by obtaining informed consent which are transferred from the doctor (the one that carried out the intervention) the patient (the one in whose favor the intervention is implemented). By informing the patient by his doctor, and short "yes" or "no" expressed by the patient on - treatment, his form makes the difference between unlawful behavior and behavior and due medical care. By being inform the patient understands that although it is aimed at improving the health status, medical intervention may lead to unfavorable consequences. By agreeing to those described by the doctor risks, the patient bears, objective treatment-related potential adverse effects that have been informed. In the absence of informed consent the doctor assumes the risk of carrying out the treatment.

To form their agreement or disagreement for the treatment, the patient, respectively persons who can give consent for him, shall receive a certain volume and type of information from the doctor. Based on its statutory duties good medical practice and ethical-moral rules, the physician personally speaks with the patient informing him in anaccessible and understandable language in sufficient volume and timely about actual health condition, the nature of the disease and need for treatment. He/she explains the purpose and nature of the treatment, reasonable alternatives, the expected results, forecasts, potential risks and benefits associated with the proposed methods and approaches for diagnosis and treatment clarifies and health risks of refusal of treatment.

This is the place to do alterity of the "standard" informed consent on what should be expressed in performing dental shooting through dental photography as a method of training in modern dentistry Unlike known to the general audience imaging, shown as an example of the first image, by means of which images are produced and interpreted are the results obtained in therapeutic and diagnostic process for patients, the method of dental photography and documentation, together with all its specifics concerns and a basic human right to personal freedom and privacy, enshrined in the Constitution of the Republic of Bulgaria. Regulation of basic human rights in the Constitution of the Republic of Bulgaria - the main and the highest ranking legislation. In art. 32, para. 2 of the Constitution states that no one shall be followed, photographed, filmed, recorded or subjected to any other similar actions without his knowledge or despite his express disapproval, except in cases provided by law.

This ban on photographing without the knowledge of the person and shooting despite disagreement, our team considered grounds for adopting the opinion that in case of use of dental photography, characterized mainly in the work of dentists, patients, respectively his parent or guardian must express informed consent in writing. This is a mandatory condition in relation to the use of the extracted images in scientificacademic and educational purposes in dental science and practice. 
It follows that any dental specialist who introduces and uses the possibilities of dental photography in his practice hasis to bear in mind that his patient has to express their informed willingness to consent or refuse medical documentation and use of image for scientific and educational purposes. Dental professionals should acquaint his patient with the fact that imaging affects only objectify the affected area, the subject of photography, all traits of the personality of the patient is deleted. And in the case of dental photography, like the general case of need for informed consent the dentist - the photographer must inform the patient about the purpose and nature of the image, the effects of its implementation, possible side effects (if any) for all specifics and alternatives.

In support of the opinion expressed below are the results from the survey conducted for the purposes of this article, which can be summarized as follows.

Scope and volume of the study. There has been a survey about attitude of total of 300 patients on the use of dental photography in dentistry in order to create an informed consent form. The survey is anonymous, after preliminary instruction on the use of dental photography in dentistry.

$>$ Timing and location of the study. The study was conducted in the period January 2015 September 2015, in the Faculty of Dental Medicine - Varna; Private Dental Practice with an aesthetic Plovdiv; Private dental practice with aesthetic focus city, Sofia;

$>$ Institutions and materials of the study The survey was conducted in various institutions of staff of the hospitals in order to objectively assess fairly the views of the respondents. A questionnaire of 10 questions is prepared with the aim to investigate the opinion of the patients for the use of dental photography in dentistry, their attitudes using confidentiality and storage of images.

$>$ Method results and a brief sample of the study. All the statistics were made in a package for mathematical and statistical analysis SPSS $\vee$ 22.0. The ANOVA statistical method was used to verify the hypothesis of equality between more than two averages. Non-parametric tests for ChiSquare $(x 2)$ and graphic method for visualization of the values of the variables were conducted. For the level of statistical significance of the results are accepted differences at a confidence level: $p<0.05, p<0.01$ and $p<0.001$.

$>$ Out of 300 patients studied, $57 \%$ or 171 are acquainted with the State and $43 \%$ or 129 are not informed about the method of SF's. (Fig.1) Only 23,30\% $(n=70)$ of those surveyed said they would be embarrassed photographic and $76.7 \%(n=230)$ would not be worried (Fig. 2). 
Fig.1. Are you familiar with the dental photography in dentistry?

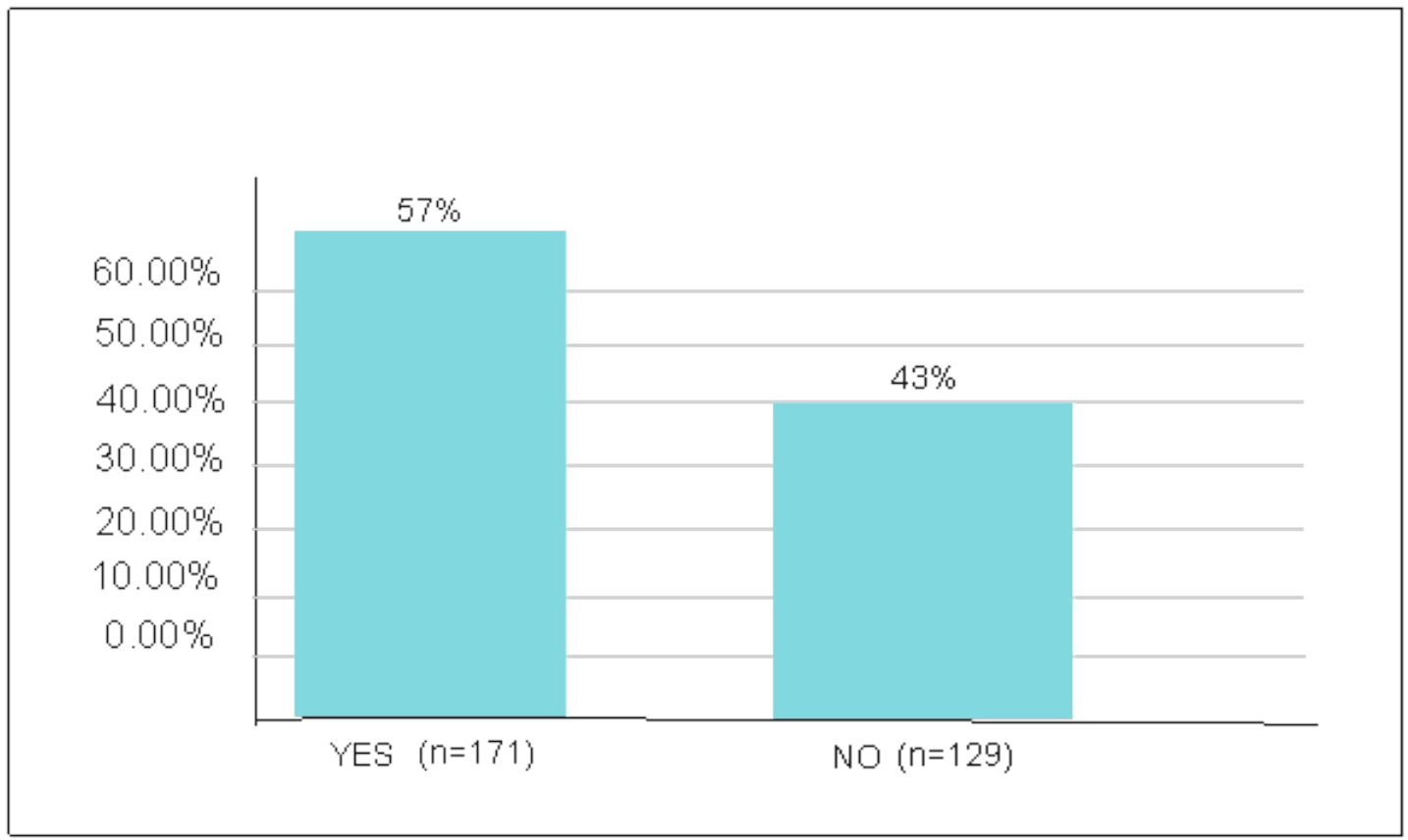

Fig. 2. You will disturb you, if you photograph?

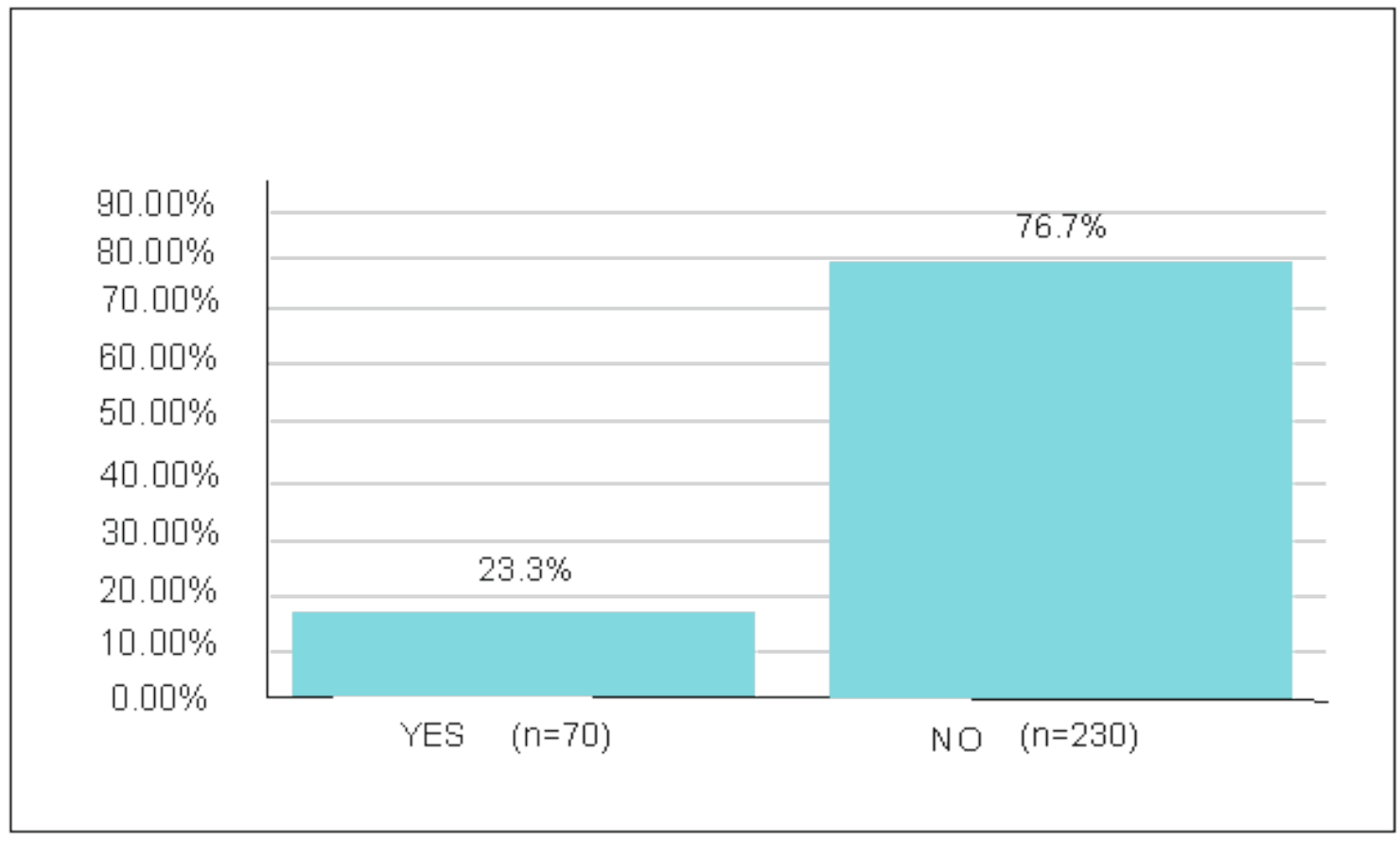


Over $61 \%$ of responders feel greater confidence to dentists using dental photography, $28.1 \%$ partially, and $10 \%$ of responders method has no effect on the confidence criterion) (Fig. 3). There is a significant difference in the opinion of patients, who are familiar with the State, and would trust more to their dentist if you used ( $x 2=36,97, p<0.001$ ) ( Fig. 4 ) shows that $83.30 \%$ of patients who indicated that they would not trust their dentist using dental photography does not really know them, while $56.80 \%$ of the patients who would trust more dentists using dental photography are actually aware of and informed about the method.

Fig.3.Would you trust more if the dentist uses dental photography?

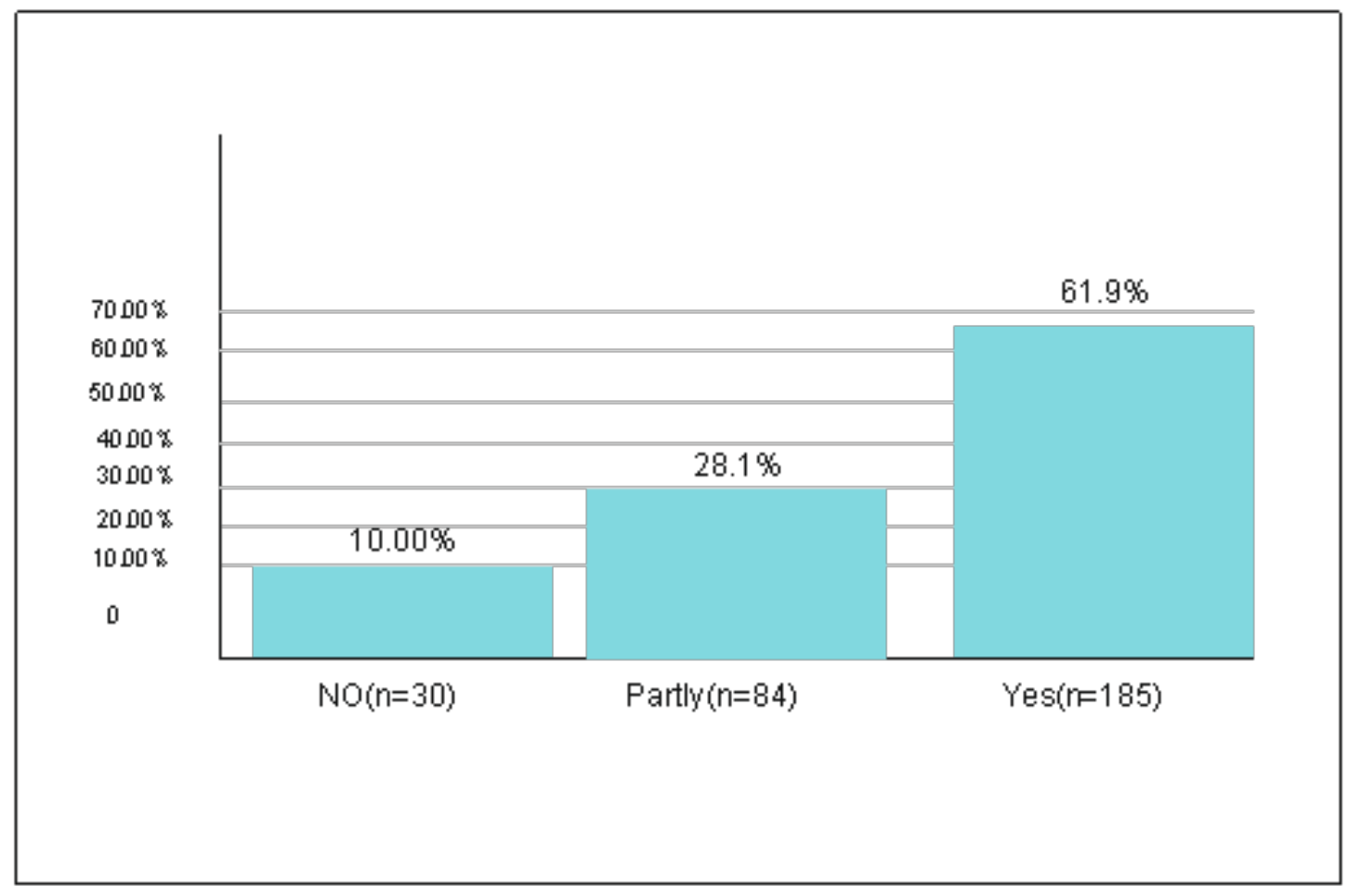


Fig.4 Are you familiar with dental photography and would you trust more to the dentist if using dental photography?

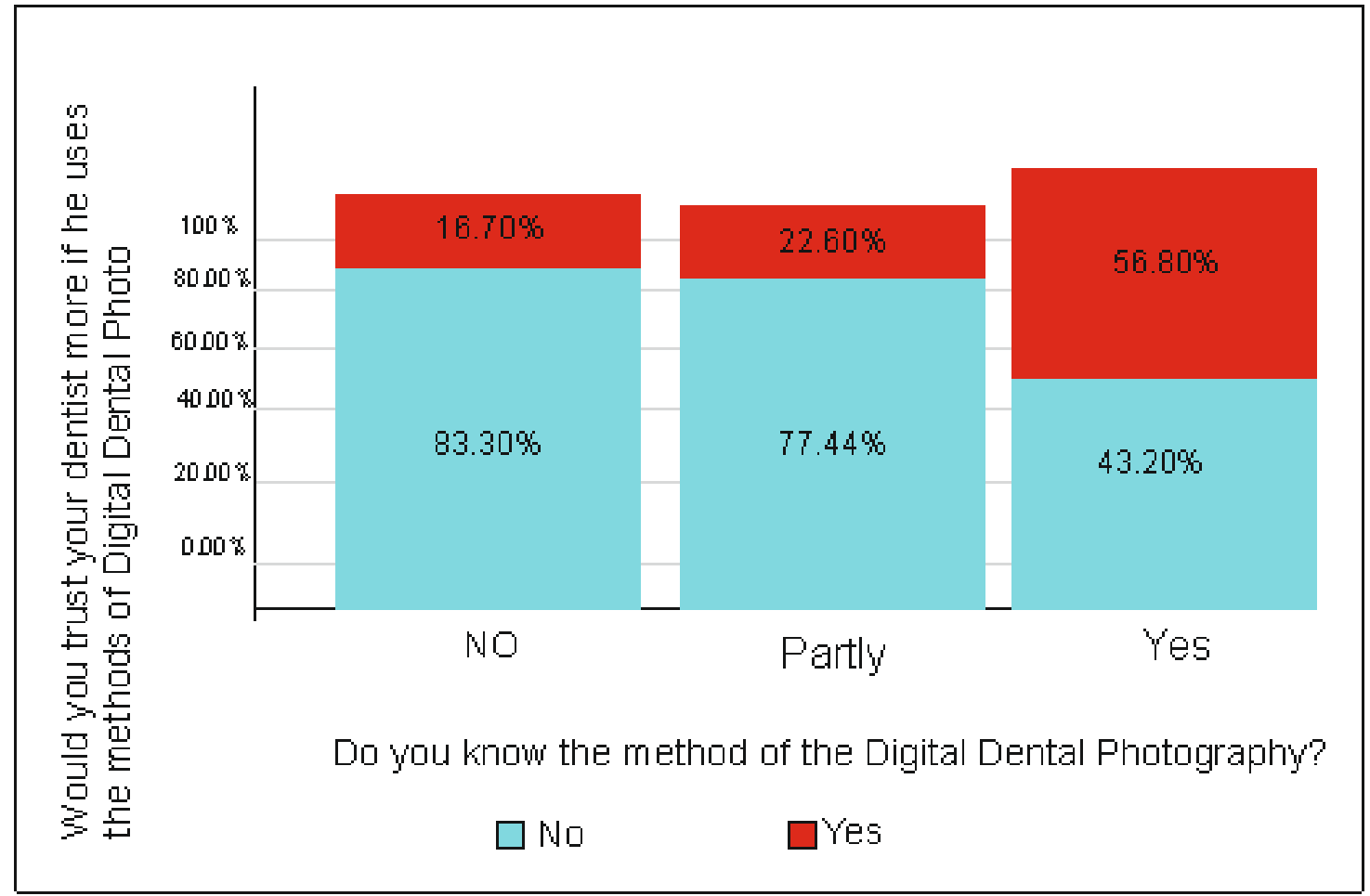

The results of survey are indicative of the need to implement the informed consent using dental photography in dentistry to avoid bilateral ambivalent reactions.

Informed consent form using dental photography for the needs of dentistry.

Made us informed consent form is consistent with the ethical and legal concepts of modern dentistry. We offer the use of this form in every dental practice that uses the method of documentary photography and documentary. 
Informed consent form using dental photography for the needs of dentistry

/ Name and address of the hospital /

/Names of the operator of dental photography/the photographer/

\section{Declaration}

of informed agreement of using dental photography

The undersigned. ID

phone/e-mail for contact:

In the undersigned informed agreement I certify that after discussion in an understandable language and sufficient volume between me and my treating dentist, I am informed for the need and application of dental pictures needed for the process of dental research, my dental status, the nature of my illness, the different stages and the end result of the dental treatment. I acknowledge, that I am informed of the purposes and nature of the dental photography. I am familiar with the possible alternatives, the expected results, forecasts, possible risks and benefits, related with the proposed method and strategies for diagnostics and dental treatment. I am familiar with the risk of not using dental photography in the visible area and with the risk for my health if refusing treatment with this method.

I declare as:

1. Patient.

2. Parent/guardian/trusted of the patient::

That I am informed personally my treating physician/dentist $\mathrm{Dr}$...... for all circumstances connected with my condition and the proposed treatment, portreted in understandable language as well as that I have had the opportunity to ask questions about everything that I considered important and managed to make an informed decision for using dental photography in my dental treatment.

3. I agree that all of my photos, taken before and during my treatment, can be used from the authorized staff for educational, scientific and academic purposes as well as stored in files and be part of the documentation of the hospital.

4. I declare my agreement that photos can be published, shown and used for scientific and educational purposes and I allow them to be used in dental photo albums, professional magazines and/or textbooks and scientific publications.

Signature of the declarator:

Signature of the dental photographer: 


\section{Conclusion}

The modern dental photography has a major role in the process of educating and qualifying dentists and the experts in dental medicine. The photographic documentation and its aspects, purposes and availability impose it as a modern method of comparing analysis when taking pictures of the patient before, during and after dental treatment.

The obligation of dentists to present information for the rights of the patient when using dental photography is a major part of the modern medical treatment. The implementation and defense of the mentioned human rights, structured in the constitution of the state, depend mostly by the knowledge of the patients about dental photography and from their own activity as participants in the process. The defense of this public interest is placed within the priorities of the professional organization in order to enforce it effectively and guarantee dental care in accordance with the best dental practice.

\section{References}

1. Ahmad I. Digital dental photography. Part 2: purposes and uses. Br. Dent. J 2009;206:9:459-64.

2. Christensen G. J. Important clinical uses for digital photography, J Am Dent Assoc. 2005;13:1:7779.

3. Loiacono P, Pascoletti L.Photography in Dentistry. Theory and Techniques in Modern Documentation; Publisher: Quintesence 2012 book

4. Ahmad I.,Digital and Conventional Dental Photography: A practical Clinical Manual. Publisher: Quintesence 2004 book

5. Bengel V. Mastering Digital Dental Photography Publisher: Quintesence 2006 book

6. 6 Mandiwall H. Visual Education in Dentistry, Proc. R Soc. Med. 1945; 38:11:646-648.

7. McFall K.J. A critical account of the history of Medical Photography in the UK, Psc Thesis 2000

8. Kakar H, Gambhir RS, Singh S et al. Informed Consent: Corner Stone in Ethical Medical and Dental PracticeJ Family Med Prim Care. 2014

9. Charter of Fundamental Rights of the European Union 2007 / C 303/01

10. Convention on Human Rights and Biomedicine, Prom. SG. 32 g 12.04.2005

11. Patient Right in the EU Bulgaria European Ethical -Legal Papers $N^{\circ} 8$

12. The Constitution of the Republic of Bulgaria

13. Health Law, promulgated. SG. No. 70 of August 10, 2004. amend. and supplemented. SG. br.27 from 5 April 2016

14. World Medical Association. Declaration of Geneva. Available from: http://www.wma.net/en/30publications/10policies/g1/ 
15. World Medical Association. Declaration of Helsinki. Ethical Principles for Medical Research Involving Human Subjects. Available from: http://www.wma.net/en/30publications/ 10policies/b3/

16. World Medical Association. International Code of Medical Ethics. Available from: http://www.wma.net/en/30publications/10policies/c8/

17. Bulgarian Code of Ethics of Dentists [Publication in Bulgarian]

18. Zinovieva D, Kenarov, P. Selected legislation and jurisprudence Bulgaria. European Journal of Health Law 1999, 6(4), 409.

19. Bhangoo $\mathrm{P}$, Maconochie IK., Batrick N et al. Clinicians taking pictures -a survey of current practice in emergency departments and proposed [10.1136/emj.2004.016972]

20. Lal S. Consent in dentistry. Pac Health Dialog 2003;10:102-105.

21. Avramova N, Yaneva K. Patients' informed consent in dental practice in Bulgaria. Oral Health Dent Manag 2011;10:80-87.

22. Radanov S. Medical deontology. S., Publication in Bulgarian, Book

23. Goleva, P. Responsibility of the doctor for damages caused to the patient. (In Bulgarian) 2004, Book

24. Annual report on the activities of Executive Agency "Medical Audit"- Bulgaria 2015 http://www.bzssm.com/index.php/237-deklaratziyata-za-informirano-saglasie;

25. Declaration of informed consent in dentistry, adopted on Bulgarian Dental Association 2015

\section{Corresponding author:}

Radostina Vasileva

Faculty of Dental Medicine, Medical University of Varna

55 Marin Drinov Str. 9002 Varna, Bulgaria;

Tel.:0876744070;e-mail: radost11dent@abv.bg 